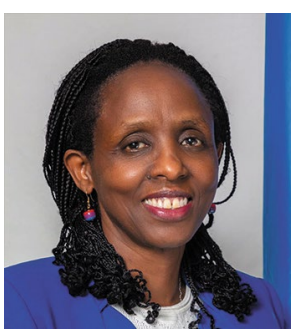

\title{
Transforming food systems is within reach
}

\author{
Enormous shifts can happen very quickly when science and policy work hand-in-glove, says \\ Agnes Kalibata.
}

Credit: UN Food

Systems Summit

became the Minister for Agriculture in

Rwanda in 2008 when the country was

facing the twin challenges of serious

hunger and rural poverty. The government policy was then - and still is - to draw on technical expertise for the implementation of programmes, particularly for agriculture. I had the opportunity to draw on all that I knew from the science and scientific networks I had developed during my time with CGIAR (formerly the Consultative Group on International Agricultural Research), where my science career grew, and to quickly superimpose evidence onto a strong policy environment that the government was prepared to put in place.

Two major viewpoints of that Rwandan government were critical to how we successfully moved forward. The first was the understanding that solutions to our problems would have to be based in our local context. The second was, quite simply, that we needed all hands on deck. No single ministry could deliver on the complex issues of food and nutrition security, and agricultural productivity against a very fragile environment, let alone a nation with a fragile state of mind, which was the case just over ten years after the genocide. Drawing on science allowed us to minimize mistakes and quickly build consensus on how to move forward while using policy to reach millions of people, who would otherwise be impossible to reach with viable solutions. Two million Rwandans - a fifth of the country at that time - were moved out of poverty in just five years, moving the country to a largely food-secure status and contributing to recovery from a horrific recent past.

In the grip of the COVID-19 pandemic, the same approach is needed the world over; we must put science before all else, and we must use policy to be swift in our actions. Food and food systems provide a lot of ground for us to build on as we strive to recover. But when science and policy work hand-in-glove, in my experience, enormous shifts can happen - quickly.

\section{Food Systems Summit}

Science-based policy for food systems transformation means much more than developing new, cutting-edge products or technologies. It also means equipping policymakers to adopt a scientific approach to a challenge, enabling innovative minds to go to work to find solutions, and putting in place an environment that allows creativity, innovation and businesses to thrive. Policies anchored in science and local context give us the biggest opportunity to be inclusive and mindful of people's needs, cultures and the environmental challenges.

Science provides us with a roadmap to reach the most appropriate solution for each context. Take, for example, producers or Indigenous people and the different geographies they live in: the priorities and resources must match the needs of specific target populations. This is the approach that underpins the first of its kind UN Food Systems Summit.

Over the past year, a Scientific Group and leading experts from civil society, convened by the Summit to lead across five priority areas, have led regular consultations through a series of public forums, surveys and community discussion groups to produce an initial 1,200 ideas. These are currently being refined into action areas and solution clusters that address the challenges facing farmers, Indigenous peoples, youth, women, hauliers, chefs and entrepreneurs across the food system.

And these groups of experts, together with huge support from member states, civil society, the private sector, UN institutions, representatives of producers and Indigenous people will shed light on potential solutions and win-win scenarios between competing priorities, as well as synergies to be navigated, mapping the different forces at play. The complexity of the issues at hand will, in many cases, require complex solutions, especially in the design of delivery and implementation.

One prevailing challenge for food systems, for example, is not only to find ways to feed a growing number of people but to do so while also reducing environmental impact and delivering the 2030 agenda.

Even if the world abandoned all fossil fuels immediately, emissions from food systems alone would likely see global temperatures rise beyond $1.5^{\circ} \mathrm{C}$ between 2051 and 2063 .

The first step towards developing appropriate solutions is recognizing that the food-climate nexus will require national strategies that vary according to natural resources, population needs and existing infrastructure. Land degradation and desertification is an enormous problem, for example, yet there are also opportunities to reverse the loss of arable land with very positive effects on biodiversity, food security, climate and income generation.

Agency is key here to ensure the most vulnerable and isolated are empowered to develop and adopt solutions that best meet their needs. This is why the Summit is working with the UN's International Fund for Agricultural Development to ensure millions of the world's smallholder farmers and Indigenous people have the opportunity to engage with the Summit's process. Ensuring agency is an expression of greater equality, allowing everyone to participate in food systems and determine what foods they eat, produce and process. And emerging solutions must be scalable, accessible and actionable, owned by countries and supported by the private sector and citizens to mobilize quickly and drive change.

With as comprehensive a picture as possible of the competing tensions between the needs of people and planet, the Summit's leadership can set out evidence across five key areas, covering innovations and solutions to improve food security and nutrition, increase sustainability, reduce poverty, tackle climate change, and build resilience.

The ability to deliver on the Summit's priorities will be influenced by four factors that are critical to delivering on all Sustainable Development Goals and to move our food systems forward: human rights, 
gender equality, finance and innovation. These are some of the critical 'levers of change' for the Food Systems Summit and are factored into the process through the cross-cutting input of experts in these areas.

All of this will provide the backdrop for UN Member State Dialogues, in which countries will develop their own context-specific pathways towards more resilient, inclusive and sustainable food systems. For each country, there is a story of the tough issues they are dealing with, the solutions they are already deploying, and the opportunities they would like to harness. The Summit will support national conveners appointed by government to structure national-level dialogues that will surface solutions already being deployed by member states, and challenges holding back delivery.

In addition, wider civil society is invited to convene and participate in Independent Dialogues, which will generate publicly available reports from discussions taking place in all forms around the world. Synthesis findings from all dialogues will be public and periodically shared to inform deliberations in all aspects of the Summit process, as well as informing locally owned actions after the Summit is over.

The result of this year-long process of evidence-gathering and cross-discipline interaction will be country-level, science-based commitments to action that include measurable targets to be announced at the pre-summit in July and at the Summit with heads of state and governments in September.

It is no simple task to try to unite everyone with a stake in food systems to try to look at things differently and prioritize building a better, stronger and sustainable future. In some cases, the Summit is asking people, among others, who have devoted their lives to studying or investing in one aspect of the food system to share a platform, find common ground and collaborate with others who would traditionally sit on the opposite side of the table.

Yet we must match the scale of the challenge at hand with our ambition, harnessing the knowledge, experience and energy on all sides and right in our midst, to transform food systems and advance good food for all. Above all, we must be courageous, recognizing full well that "none of us is safe until we are all safe".
We must not sit in silos, paralyzed by our differences and defined by our challenges, but rather, we must confront them, united by a shared vision and determination to overcome them. We do not get defined by our challenges, we get smarter, we innovate and we come out better on the other side.

I lived it and breathed it, and I saw how it can work in one country when we choose to lead with science, enact the right policies and focus not just on the wellbeing of people but that of their environment as well. As we go into Member State Dialogues, now is the time to think through how we can make food systems work for people, planet and prosperity across our entire world.

\section{Agnes Kalibata (iD)}

Special Envoy of the UN Secretary-General for the 2021 Food Systems Summit, Headquarters of the United Nations, Nairobi, Kenya.

$凶_{e-\text { mail: katie.taft@un.org }}$

Published online: 20 May 2021

https://doi.org/10.1038/s43016-021-00291-z

Competing interests

The author declares no competing interests. 